\title{
Ayudas para la marcha en la parálisis cerebral infantil
}

\section{Help for the March in the Child Cerebral Palsy}

\author{
Alberto Bermejo Franco \\ Diplomado en Fisioterapia \\ Diplomado en Podología
}

Correspondencia:

Alberto Bermejo Franco

Hospital Infanta Cristina, Departamento de Rehabilitación, Avda. 9 Junio, $\mathrm{N}^{\circ} 2$.

28981 Parla, Madrid (España)

Fecha de recepción: 30 de octubre de 2010

Fecha de aceptación: 2 de febrero de 2011

El autor declara no tener ningún tipo de interés económico o comercial.

\section{RESUMEN}

Introducción: La Parálisis Cerebral Infantil es la causa más común de espasticidad en niños y la aplicación de ayudas técnicas es una opción para el tratamiento de los déficits funcionales del niño. Objetivo: realizar una búsqueda bibliográfica acerca de las posibilidades que existen en la actualidad para llevar a cabo una rehabilitación integrada de esos déficits funcionales. Resultados: existe una amplia gama de medios tanto conservadores como quirúrgicos que se deben adaptar a las características individuales del paciente; no obstante, el análisis de los déficits ha de ser precoz para que, con un tratamiento continuo y específico, podamos llegar a un desarrollo motor del niño y a su integración en una vida que se acerque lo más posible a la normalidad. Discusión: hay autores que no tienen en cuenta las medidas ortopodológicas como medio de tratamiento en sus artículos mientras que otros afirman la efectividad de las mismas mejorando la funcionalidad, disminuyendo la sintomatología y evitando otros problemas asociados. Conclusión: comprobada la efectividad del tratamiento ortopédico en los hándicaps e individualidades de cada niño, reservaremos el tratamiento quirúrgico para los casos en que hayan fracasado los medios conservadores o para los casos más severos de parálisis cerebral infantil.

Palabras claves: Parálisis Cerebral Infantil; ayudas para la marcha; tratamiento ortopédico

\begin{abstract}
Introduction: The Child Cerebral Palsy is the commonest cause of spasticity in children and the application of technical helps is an option to child functional deficit treatment. Objective: make a bibliographic research about the possibilities which exist nowadays to carry out an integrated rehabilitation of those functional deficits. Results: there are a wide variety of means as conservative as surgical that must be adapted to the characteristics of each patient; nevertheless, there must be an early analysis of the deficits in order to get a child motor development and his integration in a life which gets closer to the normality in the most possible way with a continuous and specific treatment. Discussion: there are authors who do not take into account the orthopodologycal measures as a treatment resource in their scientist article meanwhile others claim the effectiveness of the same getting better the functionality, decreasing the symptomatology and avoiding another associated problems. Conclusion: checked the effectiveness of the orthopaedic treatment in the handicaps and individualities of each child, we will reserve the surgical treatment in cases in which the conservative resources have failed or the most stringent cases of cerebral palsy.
\end{abstract}

Key words: Child Cerebral Palsy; Help in the March; Orthopaedic Management.

Sumario: 1. Introducción. 2. Definición. 3. Manifestaciones clínicas. 4. Ayudas técnicas. 5. Ayudas a la sedestación. 6. Ayudas a los desplazamientos. 7. Ayudas técnicas para la bipedestación. 8. Ayudas técnicas para la marcha. 9. Tratamiento. Agradecimientos. Bibliografía.

Referencia bibliográfica: Bermejo Franco A. Ayudas para la marcha en la parálisis cerebral inflantil. Rev. Int. Cienc. Podol. 2012; 6(1): 9-24. 


\section{INTRODUCCIÓN}

La parálisis cerebral infantil (PCI) fue descrita en 1889 por Olsen, teniendo como antecedentes una enfermedad descrita como el síndrome de Little. Es la patología que más problemas ortopédicos plantea ${ }^{1,2}$ tras la erradicación de la polio. Tiene una incidencia aproximada del $1-5 \%$ de los nacidos vivos, con ligero predominio del sexo masculino, y una mayor incidencia en América respecto a Europa. Actualmente es la primera causa de invalidez en la infancia ${ }^{1,2}$, y otros autores la catalogan como la causa más común de espasticidad en niños ${ }^{3}$.

El patrón normal en la marcha está basado en el equilibrio como capacidad para asumir la posición erecta y la locomoción como forma de desplazamiento en el espacio. La marcha en sí es un proceso complejo y, por tanto, el análisis de las alteraciones de la misma también puede resultar diverso, según tomemos en consideración su etiología, la zona afectada, el nivel de afectación y otras manifestaciones clínicas ${ }^{3,4}$.

Los niños deben experimentar gran variedad de posiciones a lo largo del día, sobre todo aquellos con limitaciones de movimientos, con contracturas de origen postural y con deformidad. Los cambios de posición también contribuyen a una mejora en la salud cardiopulmonar, digestiva y circulatoria.

Aunque algunos pueden vivir hasta la novena década, la esperanza de vida media en ellos es de unos 34 años ${ }^{5}$.

\section{DEFINICIÓN}

Es una lesión neurológica no progresiva que se produce durante la gestación o en el nacimiento con afectación predominante motriz. Normalmente se acompaña de otros déficits como problemas de visión y auditivos, dificultad del habla y del lenguaje, alteraciones viscerales, alteraciones psicológicas (alteraciones perceptivas, distractibilidad), y discinesia. Los síndromes motores varían según la edad concepcional, etiología y localización de las lesiones o anomalías.

Existen múltiples causas que originan el daño cerebral, entre las que se encuentran: el desarrollo defectuoso del cerebro, la anoxia, la prematurez, la hipoglucemia, causas genéticas, la hemorragia intracraneal, incompatibilidad de $\mathrm{Rh}$, la excesiva ictericia neonatal, el traumatismo y la infección. En algunos casos, la causa no está clara y, en muchos otros, el hecho de conocerla no indica necesariamente un diagnóstico o historia del caso.

\section{MANIFESTACIONES CLÍNICAS}

Respecto al cuadro clínico, existen tres aspectos que se consideran fundamentales:

1. El retraso en el desarrollo en relación a la adquisición de nuevas habilidades que deberían lograrse a la edad cronológica del niño.

2. Persistencia de un comportamiento infantil en todas las funciones, incluyendo reacciones reflejas infantiles.

3. Ejecución de múltiples funciones mediante patrones jamás vistos en bebés y niños normales, debido a los síntomas patológicos como la hipertonía, la hipotonía, movimientos involuntarios y alteraciones biomecánicas derivadas de las lesiones de la motoneurona superior.

Aparecen rasgos comunes en los distintos tipos de parálisis cerebral infantil, como pueden ser: el retraso o alteración en el desarrollo de los mecanismos del equilibrio postural o de los reflejos posturales, que perjudican el desarrollo motor; y la presencia de reflejos patológicos que no son característicos de ningún tipo de parálisis cerebral en especial.

Las alteraciones ortopédicas o deformidades que afectan al sistema osteomusculoarticular tienen una frecuencia y una gravedad relacionadas con el grado de afectación motriz. La acción nociva de las fuerzas musculares en desequilibrio, así como el mantenimiento de posiciones viciosas y asimétricas durante bastante tiempo, produce un acortamiento adaptativo de los tejidos blandos. Por este motivo es de vital importancia el realizar una evaluación precoz de estas alteraciones ortopédicas y realizar un tratamiento de la manera más inmediata que trate de prevenir todas estas alteraciones ${ }^{6}$.

Las deformidades de pie y tobillo en estos pacientes son muy comunes. Las más típicas 
son: equino (normalmente asociado a varo o valgo) con espasticidad ${ }^{7}$, calcáneo valgo con excesiva flexión dorsal, metatarsus aductus con espasticidad de la musculatura intrínseca del pie, hallux abductus valgus, pie cavo con disbalance de la musculatura intrínseca y extrínseca del pie ${ }^{1,2}$.

Las clasificaciones en tipos de parálisis cerebral varía según clínicas, pero generalmente, los tipos más comunes son el espástico (del $70 \%$ al $80 \%$ de los casos), el atetoide y el atáxico (del $5 \%$ al $10 \%$ de los pacientes) $)^{2,8}$.

Las principales características motoras son:

\section{En la parálisis cerebral espástica}

El aumento de tono les lleva a adoptar posturas anormales. La excitación, el miedo o la ansiedad les pueden hacer variar el tono y las posturas. Presentan una hipertonía tipo navaja, pero pueden realizar movimiento voluntario. Se pueden presentar ataques epilépticos con más frecuencia que en los otros tipos de parálisis cerebral y su inteligencia tiende a ser menor que en la parálisis cerebral atetósica. Tienen problemas de percepción, con posible pérdida sensorial (pérdida de campo visual, pérdida de sensación de la mano...), y posibles alteraciones en la caja torácica.

Existen unos patrones de marcha típicos que están condicionados por la presencia de un tono alterado en algunos grupos musculares (flexores de cadera, isquiotibiales, tríceps sural, tibial anterior, posterior y/o peroneos), presentando una espasticidad que ocasionará a la larga, apoyos incorrectos en la bipedestación y la marcha ${ }^{9}$. Entre las formas espásticas más usuales se observan: hemiplejía (el paciente columpia la pierna afectada hacia fuera en un círculo, haciendo circunducción, o la empuja hacia delante), diplejía (ocasio nando marcha "en tijeras"), y tetraplejía (llegan a adquirir una marcha autónoma, presentando un grado menor de espasticidad que los niños con diplejía).

\section{En la parálisis cerebral atetoide}

Se denomina así a este tipo porque realizan movimientos atetósicos, es decir, movimientos sin un propósito adecuado que pueden llegar a ser incontrolables. Derivado de ello tienen un control postural anómalo y presencia de danza atetósica por movimiento continuo de los pies. Los movimientos voluntarios son posibles, pudiendo tener hipotonía o hipertonía indistintamente y con cambios en el tiempo. Tienen una personalidad extrovertida acompañado de buena inteligencia, con frecuencia. También puede darse dificultades en el habla y problemas respiratorios, posible parálisis en los movimientos de los ojos para centrar la mirada, y es posible la pérdida auditiva de un tipo específico de frecuencia alta.

Los niños con atetosis, sin espasmos significantes, suelen tener un tono postural bajo que oscila a tono alto. El patrón del paso en las extremidades inferiores es normalmente alto en flexión y luego baja en la fase de apoyo en una extensión con aducción, rotación interna y flexión plantar. Las caderas están ligeramente flexionadas, la columna lumbar hiperextendida, la columna torácica redondeada y la columna cervical hiperextendida9.

\section{En la parálisis cerebral atáxica:}

Nos encontramos con movimientos voluntarios torpes o con fallos de coordinación que provocan alteraciones en el equilibrio. Es frecuente la hipotonía, con bajo nivel de inteligencia, especialmente cuando existen de forma conjunta problemas visuales, auditivos y perceptivos. Pueden aparecer nistagmus.

La marcha se caracteriza por la incoordinación de la marcha. La estación bípeda puede ser muy insegura y requerir una notoria amplitud de la base de sustentación, también se carac terizan por lentitud al iniciar el movimiento y una hipermetría en su realización ${ }^{9}$.

\section{AYUDAS TÉCNICAS}

Consideramos ayudas técnicas a aquellos productos, instrumentos, equipos o sistemas técnicos utilizados por una persona con discapacidad, fabricados especialmente para ella o disponibles en el mercado, para prevenir, compensar, mitigar o neutralizar la deficiencia, la incapacidad o la minusvalía. Las ayudas técnicas y adaptaciones pueden ser capaces de compensar, parcial o totalmente, situaciones de discapacidad, de reducir la minusvalía y, por tanto, de aumentar el nivel de independencia 


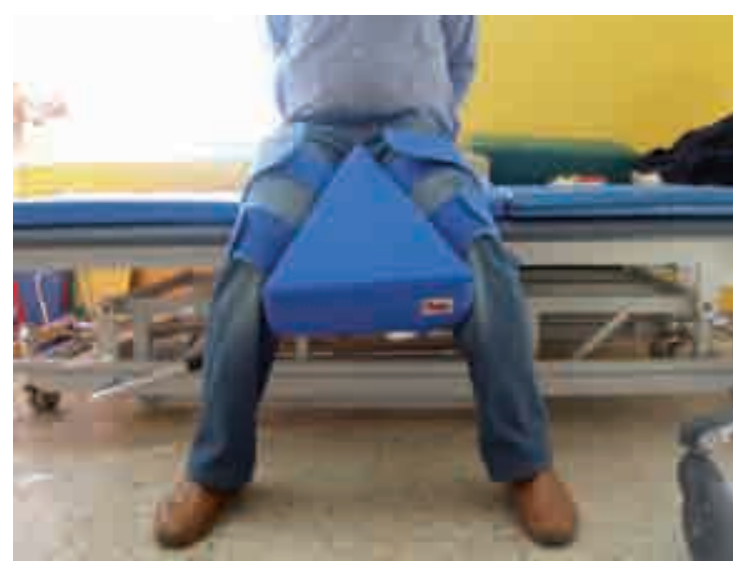

Fig. 1. Asiento Triangular.

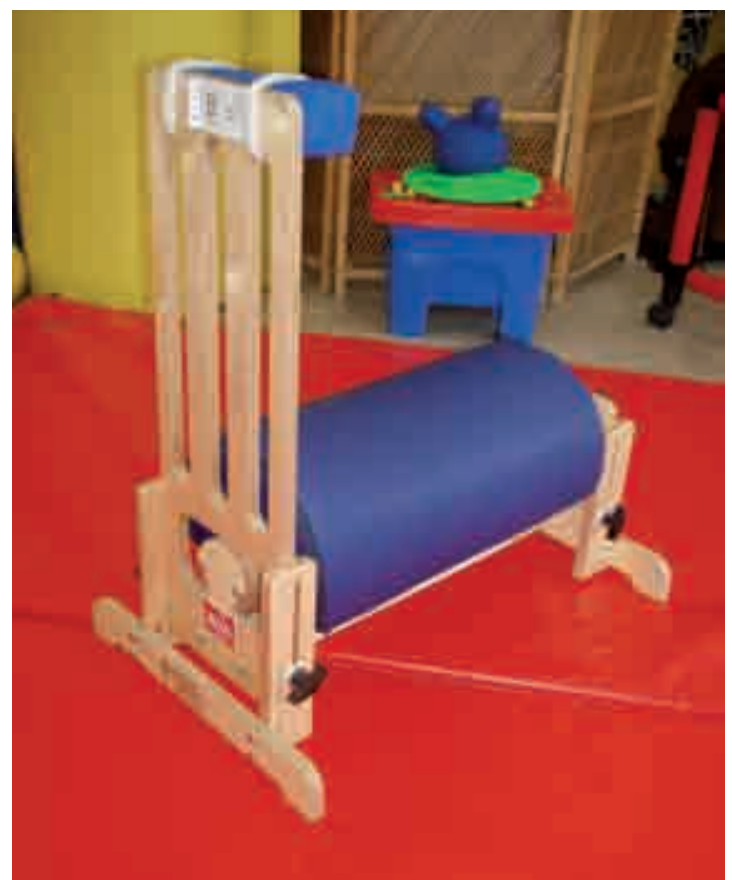

Fig. 2. Posicionador.

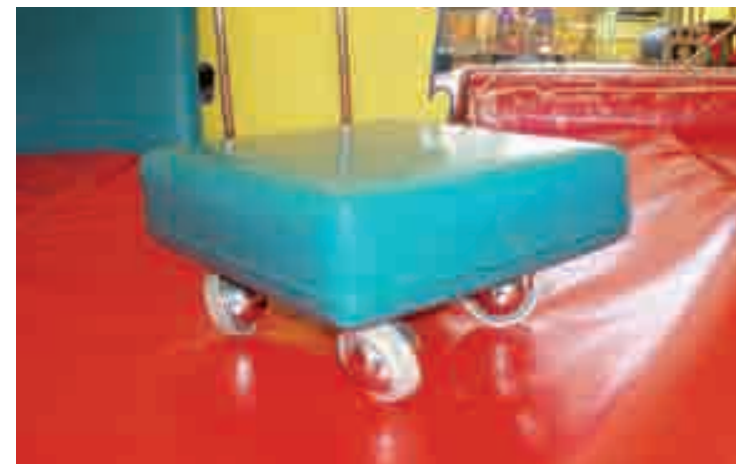

Fig. 3. Plano de arrastre. funcional y mejorar, notablemente su calidad de vida.

Aunque en este artículos nos centremos en las ayudas técnicas para la movilidad personal del paciente, existen otro tipo de ayudas técnicas como son: ayudas para el cuidado personal (esponja con mango alargado, sillas de bañera, jarra de plástico con asas, velcros para calzado y ropa, aro para subir cremallera, abotonador, botellas de orina de plástico), ayudas técnicas para la comunicación (adaptaciones en teléfono, comunicadores), ayudas para la discapacidad sensorial (visual o auditiva), ayudas para el ocio y otras ayudas técnicas ${ }^{10}$.

Las modificaciones del entorno a través de material adaptado se usan para promover cambios en el control motor, más que para producir cambios manipulando físicamente al niño.

Deben tener siempre en cuenta las características individuales de cada niño, y deben ser revisadas constantemente a la vista de los cambios que se produzcan con el tiempo. El diseño y una adecuada elección del material es fundamental para garantizar la correcta aplicación del tratamiento. El material adaptado se emplea para aumentar las capacidades motrices funcionales o bien como parte de un programa terapéutico y/o educativo, y para mejorar la independencia de movilidad, de juego y de in teracción social.

\section{AYUDAS A LA SEDESTACIÓN}

La sedestación se favorecerá precozmente en el tratamiento fisioterápico, pudiendo utilizarse ayudas ortopédicas del tipo del asiento triangular (Fig. 1), que favorece el control del tronco e impide la extensión de la cadera y la abducción. Los cochecitos normales para estas edades deberán reforzarse en el respaldo, colocando sujeciones para tronco y separación de los miembros inferiores, con el fin de prevenir alteraciones en la alineación del niño con parálisis cerebral infantil ${ }^{11}$. Como ayudas para la sedestación podemos utilizar cuñas, cuñas con cinchas, rodillos, posicionadores (Fig. 2), almohadas para tratamiento de hipertonía de aductores, y otros dispositivos que corrijan y/o estabilicen.

6. AYUDAS A LOS DESPLAZAMIENTOS 
Se trata de estimular la capacidad activa del desplazamiento del niño. Pueden emplearse planos de arrastre (Fig. 3), gateadores (Fig. 4) de distintos modelos con ruedas giratorias y cinchas graduables para la sujeción del tronco.

\section{AYUDAS TÉCNICAS PARA LA BIPE- DESTACIÓN}

La posición bípeda forma parte de la herencia humana y proporciona una sensación de bienes tar, energía y vigilancia. Este estado de bipedestación es muy importante para un niño con parálisis cerebral infantil porque: previene el desarrollo de contracturas de los miembros inferiores y el dolor que de ellas se deriva, reduce notablemente la espasticidad, produce beneficios sobre el sistema circulatorio evitando la formación de edemas y previniendo y mejorando la formación y curación de las úlceras por presión, y tiene efecto sobre la densidad de los huesos porque favorece un crecimiento normal del esqueleto con la solicitación que de la bipedestación se deriva a la par que previene la osteoporosis y las consiguientes fracturas que pueden ocasionarse consecuentemente.

El desarrollo de la capacidad de levantarse no sólo es esencial para la marcha sino también para la conducta independiente en otras actividades del ser humano. No obstante, el hecho de levantarse requiere la capacidad de extender las articulaciones de los miembros inferiores sobre una base de soporte fija que son los pies.

Se trata de conseguir una bipedestación lo más activa posible o, lo que es lo mismo, la menor sujeción necesaria. Los programas de carga consisten en el uso de diferentes materiales adaptados de tal forma que traten de conseguir la bipedestación del niño cuando el control motor es inadecuado para permitirle estar de pie sin la ayuda de estos recursos.

Como elementos técnicos facilitadores de la bipedestación, podemos destacar:

\section{- Plano ventral}

Consiste en colocar al niño en posición prona con sujeción en el tronco, pelvis y extremidades, con una inclinación variable según la tolerancia y los objetivos terapéuticos. Se emplea especialmente en niños con hiperextensión de cuello, retracción de escápulas, asimetría de tronco, falta de equilibrio muscular, o dificultades para controlar alineadamente la cabeza y tronco en contra de la gravedad. Su principal objetivo terapéutico son los beneficios fisiológicos de las cargas de peso en bipedestación. (Fig. 5)

\section{- Bipedestador supino}

Es similar al plano ventral pero consiste en colocar al niño en posición supina sobre el plano, permitiendo una mayor interacción con el entorno y una percepción más natural del medio. No da soporte a los miembros superio

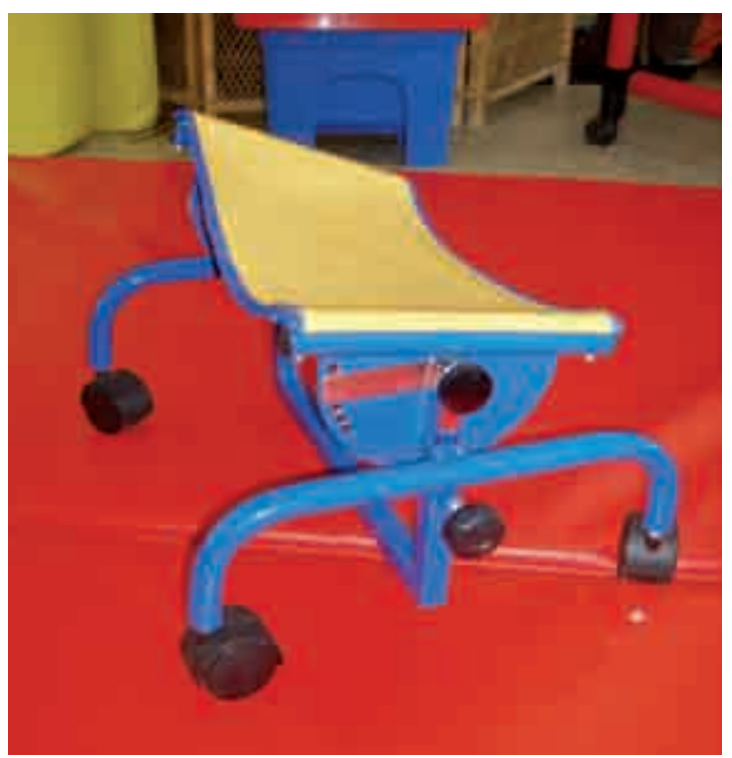

Fig. 4. Gateador ajustable en altura.

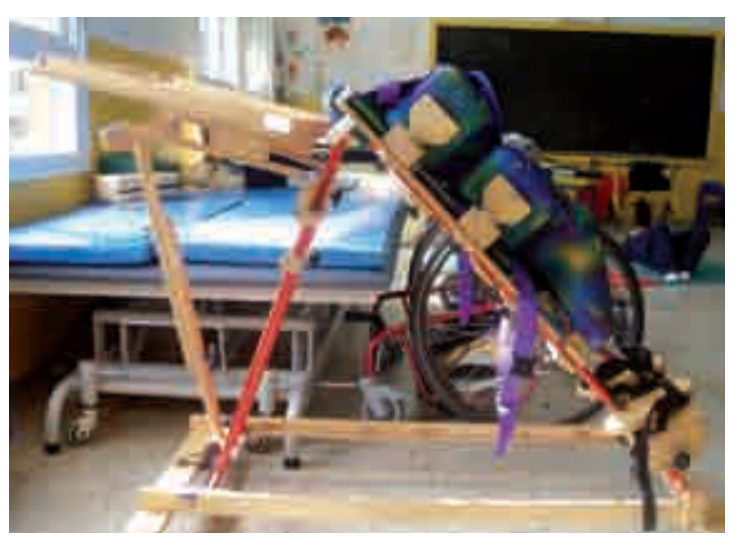

Fig. 5. Plano ventral con tablero. 
res. En este caso se deben valorar posibles compensaciones como cifosis con protusión de cabeza o hiperextensión de la columna cervical con asimetría secundaria a la falta de equilibrio y control muscular. (Fig. 6 y 7)

\section{- Standing}

Se emplea en niños capaces de controlar cabeza y tronco en contra de la gravedad, pero sin control suficiente de piernas y pelvis para poder mantener la posición de bipedestación estática. Prepara la deambulación, promueve la simetría, la alineación musculoesquelética en verticalidad y el desarrollo y crecimiento acetabular.

\section{- Standing en abducción}

Es una modalidad del standing, empleada particularmente en niños con tetraplejía y diplejía espástica cuya espasticidad de aductores interfiere en la estabilidad postural en bipedestación, tratando de equilibrar la musculatura abductora (débil y alargada) con la musculatura aductora (espástica). De esta manera evitaremos la tendencia a coxa valga que, junto a la aducción, agrava el apoyo de la cabeza femoral y aumenta

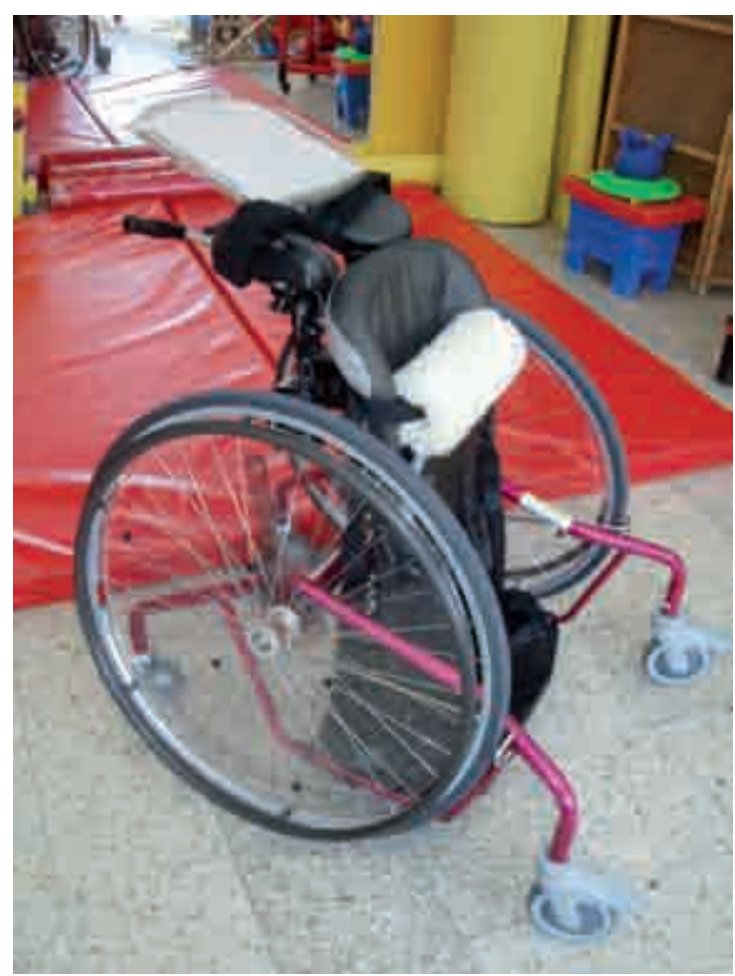

Fig. 6. Bipedestador supino. la tendencia hacia la displasia de caderas. La combinación de este programa de carga con la toxina botulínica permite obtener mayores resultados ${ }^{3}$.

\section{- Ministanding}

Es otra variedad del standing en la que la sujeción llega sólo hasta por debajo de las rodillas. Está diseñado para niños que mantienen la verticalidad pero que no pueden usar las diferentes sinergias musculares que sirven para el mantenimiento del equilibrio, y para aquellos incapaces de desarrollar respuestas posturales anticipadoras con sus propios movimientos voluntarios como los niños con disfunción vestibular y ataxia.

\section{AYUDAS TÉCNICAS PARA LA MAR- CHA}

Las ayudas para la movilidad permiten al niño explorar el entorno mientras adquiere esa sensación de independencia y competencia que hemos nombrado anteriormente. La capacidad

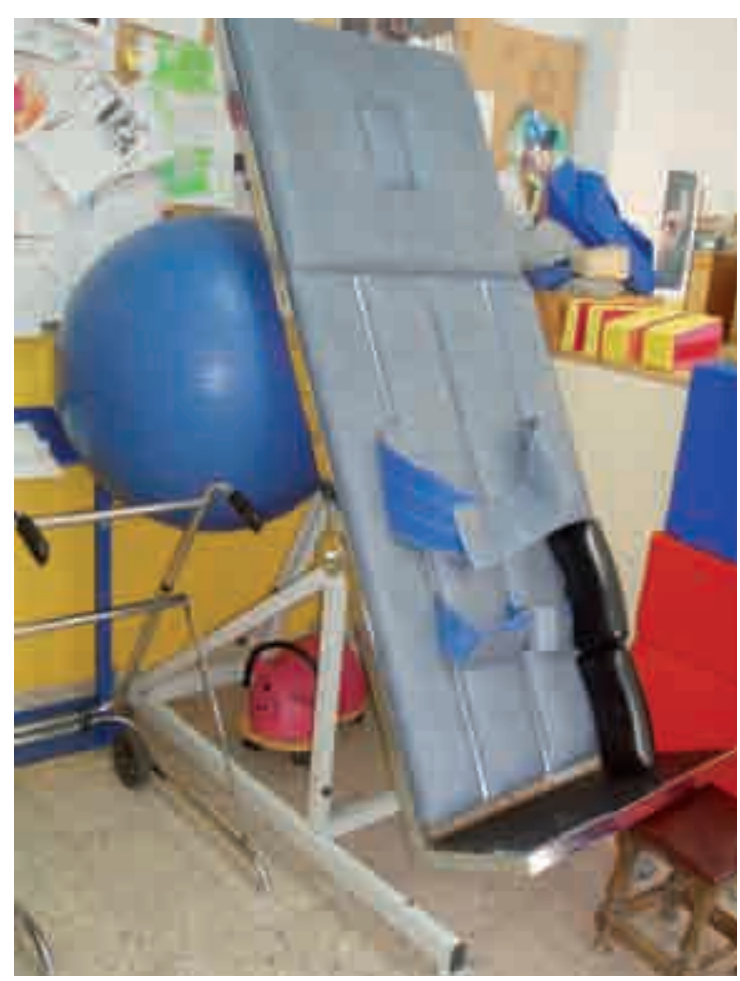

Fig. 7. Bipedestador o plano inclinado. 
de moverse promueve el desarrollo de la iniciativa, así como la adquisición de conceptos espaciales. Por tanto, la capacidad de moverse no debe reducirse a la sesión de tratamiento sino que debe ejercitarse con una ayuda adecuada, según la edad del niño, su condición física en particular, y dentro de su entorno natural.

La marcha independiente se produce entre uno y tres años. Para establecer un pronóstico sobre la marcha, se deben valorar signos de alerta y de sospecha como la persistencia de siete reflejos posturales tras doce meses de vida: el reflejo tónico asimétrico del cuello, el reflejo de enderezamiento del cuello, el reflejo Moro, el reflejo tónico simétrico del cuello, reacción de caída, posición de pie en carga, y reflejo de extensión. Si existe cualquiera de ellos pasado esa edad, producirá un pronóstico malo para la marcha ${ }^{12,13}$.

El patrón normal de la marcha está basado en el equilibrio como capacidad para asumir la posición erecta y la locomoción como forma de desplazamiento en el espacio. La marcha en si, es un proceso complejo y por tanto el análisis de las alteraciones de la misma también pue-

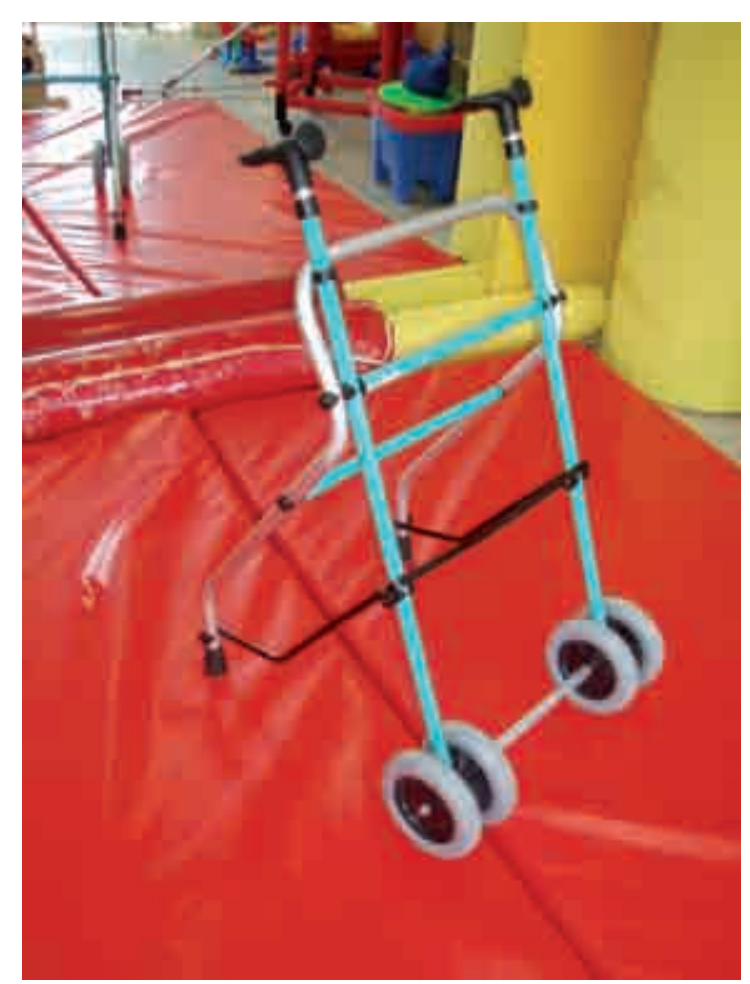

Fig. 8. Andador anterior. de resultar arduo. La afectación de la marcha en pacientes neurológicos presenta grados muy diferentes, tanto por sus formas clínicas como por sus características personales, por lo que es posible una propuesta de carácter general, requiriendo, por tanto, un tratamiento personalizado $^{4}$.

Dentro de este apartado nos encontramos con diferentes ayudas técnicas:

\section{- Marcha en barras paralelas con espejo}

Se utilizan para que el paciente logre el equilibrio de pie. Con ello se enseña la técnica de levantarse en la posición de bipedestación, alzando todo el peso corporal bajo un control pleno. También se enseña a incorporarse estando sentado y a volver a sentarse desde la posición de pie. Una vez alcanzado el equilibrio de pie con un grado adecuado de apoyo necesario, se ponen en marcha los trabajos para el equilibrio dinámico, que supone realizar giros con seguridad, patrones de marcha balanceando el cuerpo hacia delante hasta el punto de apoyo superándolo, y la técnica de marcha sobre cuatro apoyos para practicar los $\operatorname{pasos}^{14}$.

\section{- Andadores}

Con estos dispositivos los pacientes realizan una marcha semejante a la de las paralelas, pero con la facultad de desplazarse junto a los aparatos, lo que proporciona mayor indepen dencia. Su uso les da una gran seguridad, ya que, además de un buen equilibrio les procura mayor tranquilidad psicológica ${ }^{11,15}$.

Existen varios modelos que pueden ser fijos o articulados, con conteras o con ruedas. La elección de unos u otros está en función de las características individuales del paciente. Dentro de este apartado, podemos incluir una gran variedad de ayudas mecánicas que facilitan el desplazamiento de estos niños con parálisis cerebral infantil: frenos, asientos, sujeciones, barras auxiliares...

Para los niños con mayores dificultades existen dos tipos de andadores que se pueden recomendar: el más tradicional es el andador anterior (Fig. 8), en el que el niño se coloca frente a él, y el andador posterior (Fig. 9), en el que el niño se coloca anteriormente al andador y lo sujeta lateralmente. Ambos ofrecen estabilidad, sin embargo, el andador posterior favorece una 
postura más erecta, lo que conlleva un mejor alineamiento de la postura en vertical ${ }^{15}$.

Los andadores con soporte ventral estimulan la actividad del niño, facilitan la exploración, convierte las capacidades residuales en funcionales, incrementa la maduración psicomotriz, y proporciona una mayor autonomía para el desplazamiento ${ }^{16}$. Su diseño permite evitar patrones posturales anormales y de movimientos, inhibiendo la predisposición laxante de la hipertonía de aductores de cadera, protegiendo la columna vertebral, y facilitando la integración de la estática de la cabeza. Existen diferen tes tipos de andadores con soporte ventral: unos pueden tener sujeción solamente en la cintura pélvica (Fig. 10), otros pueden sujetar la pelvis y el tronco (Fig. 11), y algunos pueden incluso tener sujeciones para los hombros. Como accesorios de este tipo de andadores podemos citar el divisor de la pierna, sistemas de bloqueo de la abducción, bandejas...

\section{- Bastones}

El uso de bastón está indicado en: parálisis que afectan la musculatura de la raíz de los miembros, especialmente el glúteo mayor y el trí-

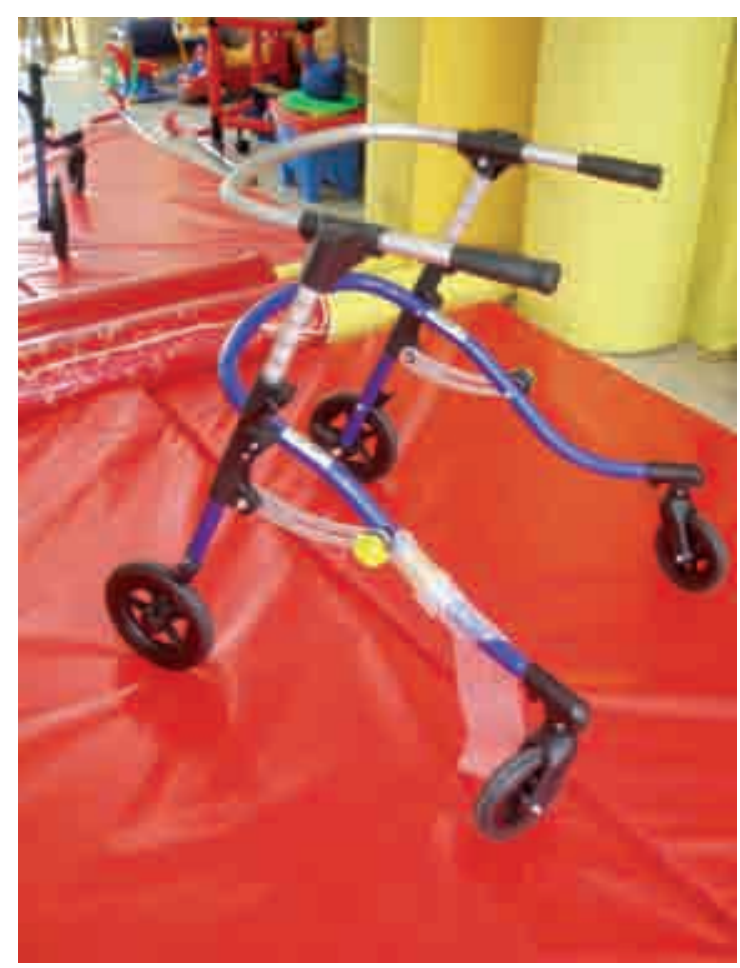

Fig. 9. Andador posterior. ceps sural; en desequilibrios producidos durante la marcha; en casos necesarios de descarga parcial de una o ambas extremidades ${ }^{11}$.

En el caso de la parálisis cerebral infantil se recomiendan cuando el niño va mejorando el control de la bipedestación pero aún no es capaz de realizar una marcha independiente y funcional. Para su uso es fundamental la fuerza en los miembros superiores $\mathrm{y}$, de esta forma, que pueda coordinar los bastones con el avance constante de las piernas. Se utilizan para proporcionar mayor libertad de movimientos, siendo más funcional y ocupando menos espacio, a la vez que mejora la coordinación de los miembros.Éste método nos permite ir reduciendo el apoyo hasta el uso de un bastón individual si hemos afianzado previamente su seguridad, su simetría y su equilibrio en la marcha.

Los bastones modificados o trípodes (Fig. 12) raramente están indicados de manera definitiva, sino que constituyen un paso intermedio entre la marcha en las paralelas y la deambulación con bastones ingleses o bastones simples $^{11}$.

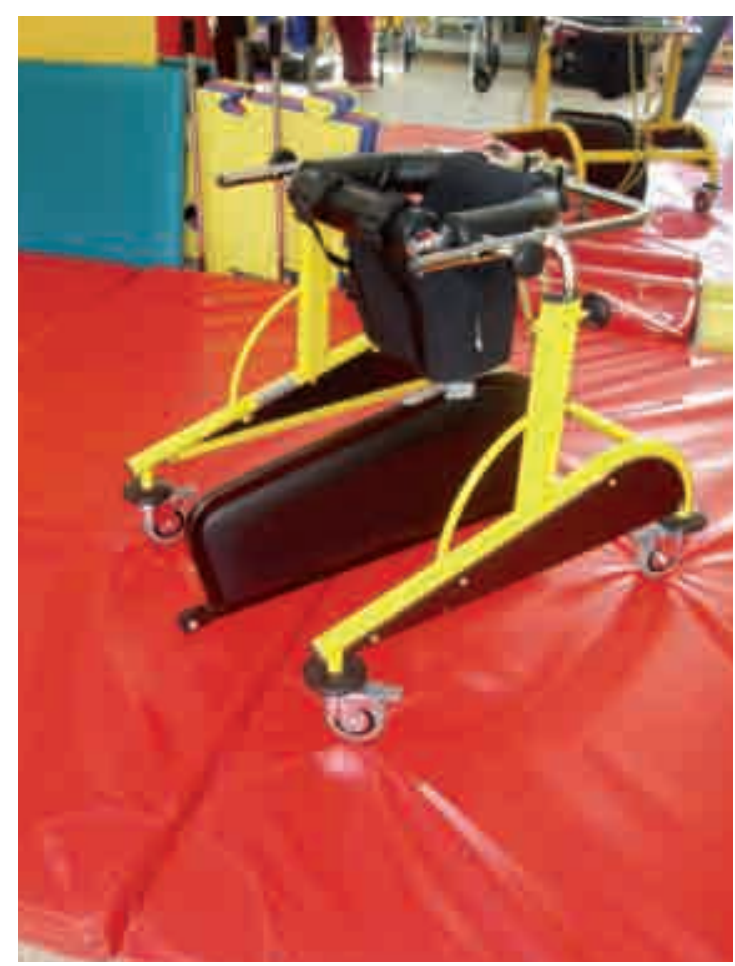

Fig. 10. Andador con soporte ventral. 2012, Vol. 6, Núm. 1,9-24 


\section{- Bastones ingleses}

Tienen las mismas indicaciones que los bastones simples pero, además, proporciona un apoyo y un equilibrio importantes para el paciente. (Fig. 13 y 14)

\section{- Muletas}

Son más eficaces para realizar la marcha pendular que los bastones ingleses, y proporcionan buena estabilidad y equilibrio, ya que realizan

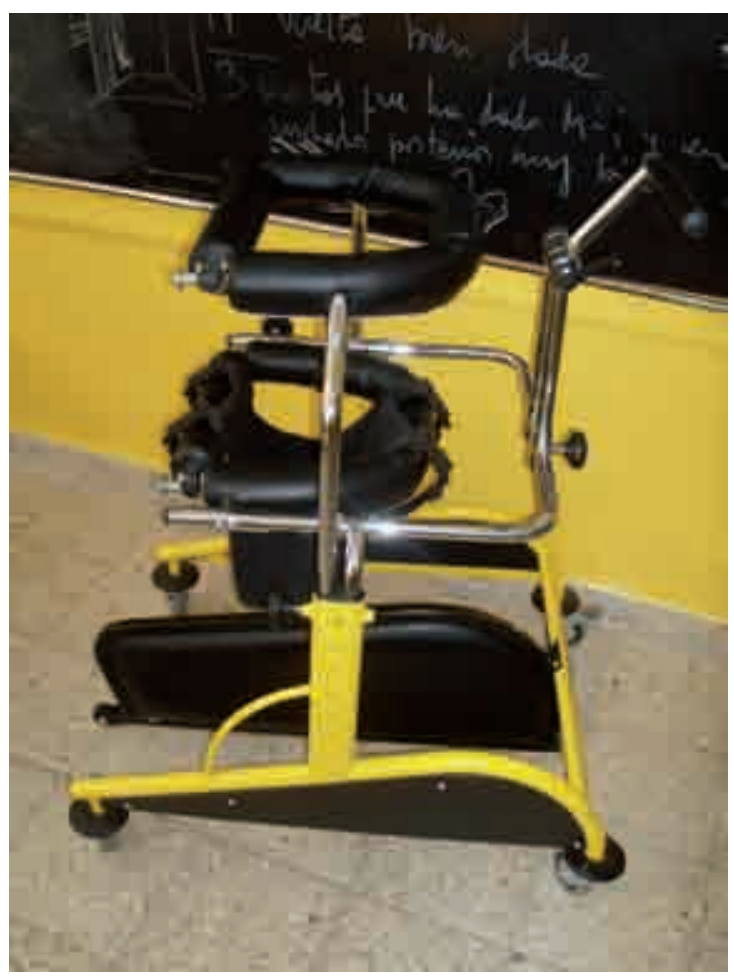

Fig. 11. Andador con soporte ventral.

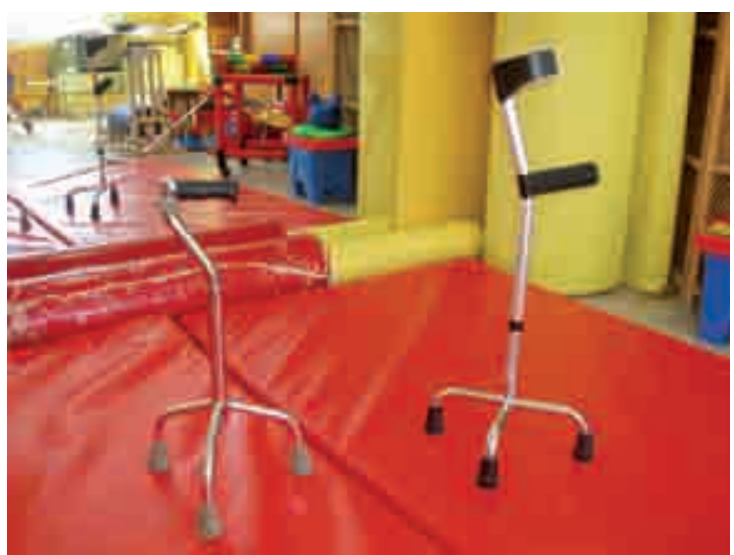

Fig. 12. Bastones modificados o trípodes.

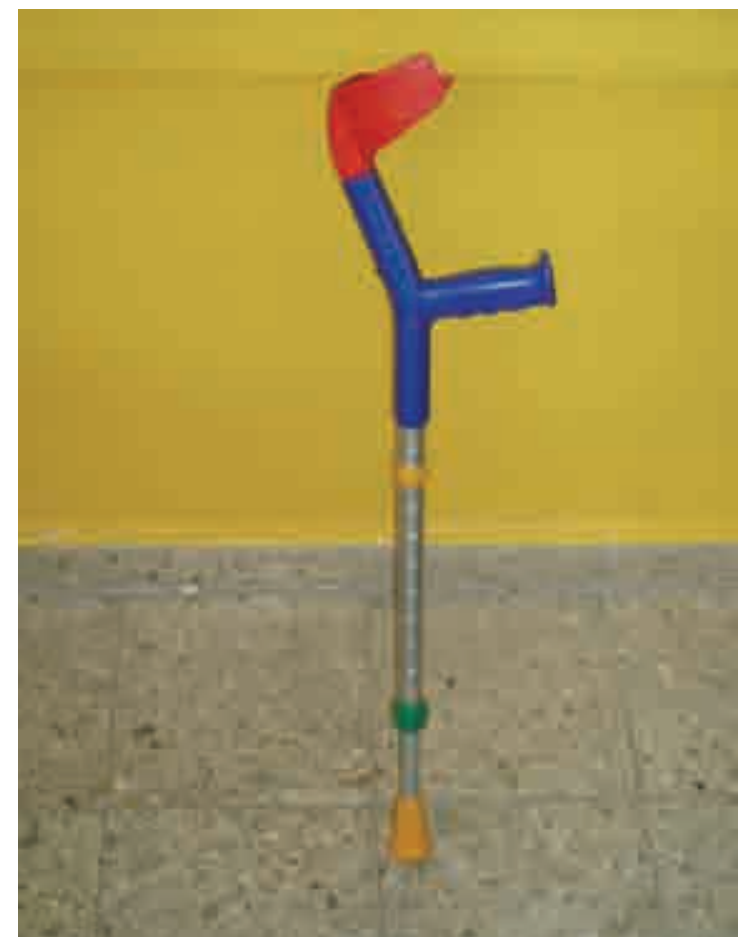

Fig. 13. Bastón inglés infantil.

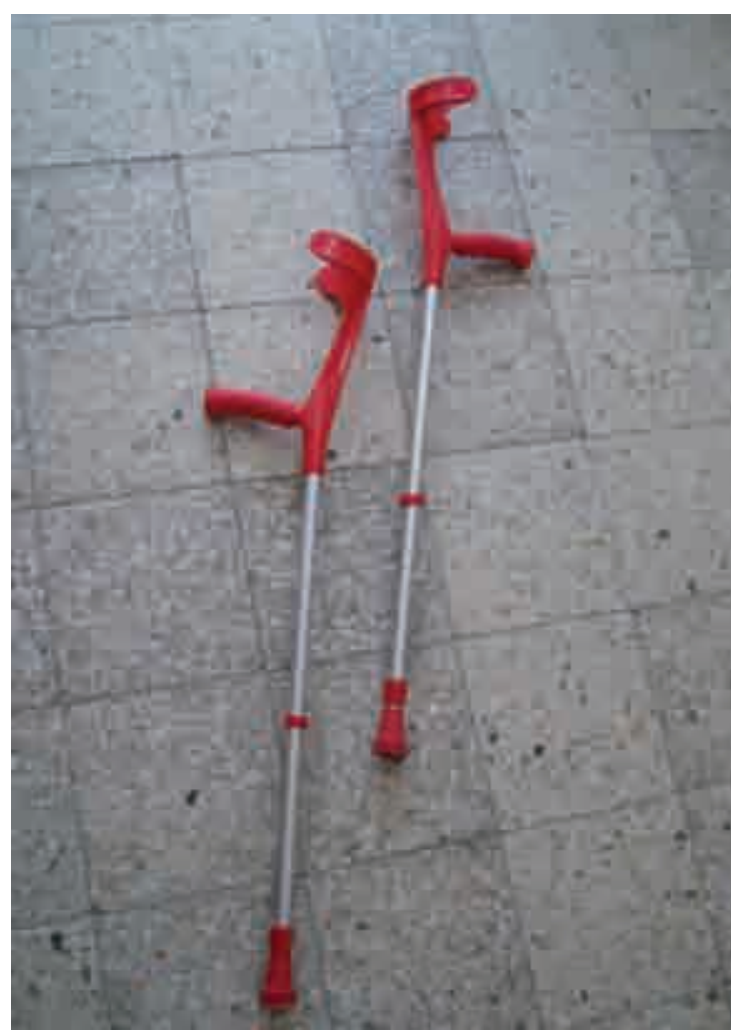

Fig. 14. Bastón inglés. 
un apoyo directo sobre el tronco ${ }^{11}$. Se emplean fundamentalmente cuando el paciente es incapaz de realizar el apoyo en sus miembros inferiores.

\section{- Triciclo adaptado}

Es un triciclo convencional (Fig. 15) al que se le puede añadir cualquier elemento necesario para el uso de estos pacientes, como por ejemplo una contención adicional que fije el tronco. Su utilización facilita que el niño genere fuerza disociada en los miembros inferiores a medida que va avanzando.

\section{- Sillas de ruedas}

La silla de ruedas es un vehículo individual utilizado para favorecer el traslado de personas cuya afectación les impide la deambulación de forma permanente o temporal $1^{11,15}$.

Existen gran variedad de modelos en función del tipo de invalidez que presente el paciente y de los fines que se busquen, y de biendo adaptarse a las capacidades de cada niño: movimientos voluntarios, gestos... Por ello, algunas poseen respaldo reclinable, cinturones de seguridad, cinchas, accesorios para separar las piernas en abducción, reposabrazos, bandeja moldeada, reposacabezas, portamuletas, mochilas...

\section{Podemos encontrar:}

- Sillas de ruedas manuales: indicadas para niños con un buen manejo de miembros superiores y sin asimetrías posturales importantes.

- Sillas de ruedas eléctricas: para niños con un buen nivel cognitivo, asimetrías importantes, o para pacientes mayores en los que el manejo de la silla manual por parte de los padres se hace más dificultosa.

\section{TRATAMIENTO}

En las etapas precoces de la vida es recomendable el contacto con el neonatólogo, pediatra o neuropediatra, en el momento de valorar y diagnosticar el riesgo de secuelas. En ocasiones, cuando la lesión cerebral es muy se vera, la predicción de déficit y la consecuente discapacidad será relativamente fácil de realizar. Sin embargo, aún en estos casos, a nivel individual es difícil el pronóstico del grado de discapacidad en las distintas áreas y para épocas más tardías de la vida ${ }^{17}$.

Una primera condición en el tratamiento es la de ser individualizado y realista, lo cual conlleva el planteamiento de unos objetivos razonables a alcanzar. Partiendo de la irrever-

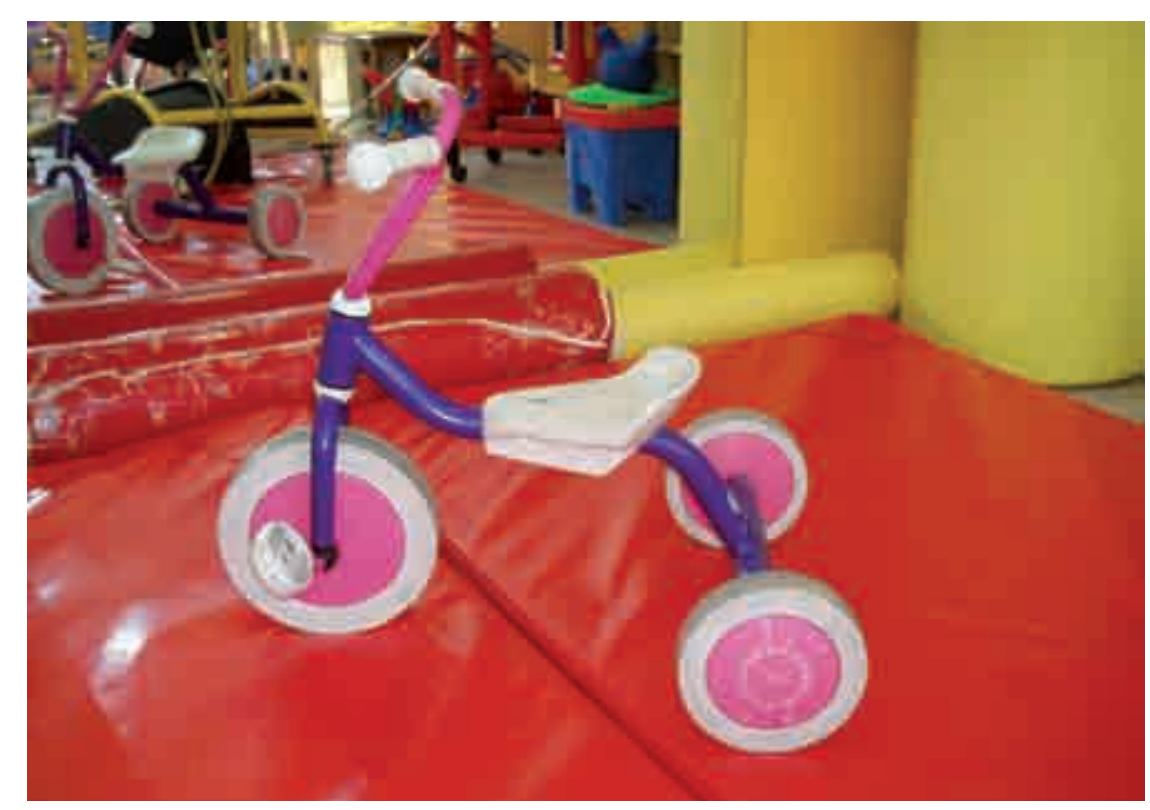

Fig. 15. Triciclo convencional. 
sibilidad de la lesión cerebral pero, al mismo tiempo, basándonos en la posibilidad de suplencias cerebrales y en la demostrada prevención de deformidades, buscaremos las mejoras funcionales para una mayor calidad de vida del discapacitado paralítico cerebral ${ }^{10,11}$. Hay que intentar lograr una escolarización y una formación adecuada y unas habilidades físicas y sociales para evitar el aislamiento y para llegar a obtener una autosuficiencia que le permita una integración social plena para realizar una vida independiente.

Incluso cuando se proponen objetivos alcanzables hay que considerar si, una vez alcanzados, mejorarían de algún modo la calidad de vida del niño, por ejemplo, hay ocasiones que conseguir una deambulación de un niño con aparatos y bastones no significa una mejora en la calidad de vida del niño en relación con los desplazamientos en silla. Así es frecuente observar a padres y terapeutas obsesionados por conseguir que el niño dé unos pasos por interiores, dejando en segundo plano aspectos de su habilitación que serían más significantes y útiles. Por todo ello, hay que fijar un orden de prioridades en los objetivos de la rehabilitación: primero la comunicación, después la independencia, el desplazamiento $\mathrm{y}$, por último, andar ${ }^{18}$. En pacientes sin pronóstico de marcha, el objetivo del tratamiento siempre será preventivo buscando la disminución de alteraciones posturales y alteraciones familiares para lograr una mejora en la calidad de vida ${ }^{2}$.

Se recomienda la edad escolar para tratar las limitaciones funcionales que aparezcan, a través de actividades adaptadas al nivel de conducta y comprensión del niño con parálisis cerebral infantil. Ningún programa de reeducación fisioterápica debe desconocer las posibilidades psíquicas del niño y el grado de coope ración y aceptación del esfuerzo que implica esta reeducación ${ }^{15,18}$. Otra condición en el programa terapéutico es que ha de ser completo, con pretensión de atender a todas las necesidades del niño, aunque no dejará de tener en cuenta los recursos familiares y comunitarios que lo hagan realizable en la práctica ${ }^{2,10,11,19}$. De nada sirve que existan ayudas técnicas y otros medios terapéuticos adecuados si no se pueden adquirir por falta de recursos.
Antes de poder reconocer el comportamiento motor anormal y general de éstos pacientes, el terapeuta debe saber todo lo que hace un niño normal y cómo lo hace en las distintas etapas de su desarrollo para que, de esta forma, pueda orientar el tratamiento a los hándicaps e individualidades de cada niño en concreto ${ }^{8,20}$. Para lograr una marcha estable normal es necesaria la madurez completa del sistema nervioso central y el cumplimiento de una serie de requisitos como son: la estabilidad durante el apoyo, la conservación de energía mediante el control del desplazamiento del centro de gravedad, y la existencia de progresión producida por la caída del cuerpo hacia delante.

Es fundamental contar en todo momento con un equipo multidisciplinar que sigan un criterio y funcionamiento en equipo para poder tratar de una forma adecuada y absoluta al niño, orientando correctamente a los padres y demás familiares o amigos, y obteniendo así una colaboración total que redundará indiscutiblemente en la evolución favorable del niño $0^{2,10,21}$.

\section{TRATAMIENTO NO QUIRÚRGICO}

Dentro de este apartado, podremos encontrar:

\section{Terapia física y/o Ocupacional}

Tiene la finalidad de reducir la gravedad del proceso o incluso curarlo en su aspecto más visible que es el aparato locomotor. Para ello, se emplean tratamientos como Bobath, Vojta, Rood, Kabat-Knott (FNP) y Phelps entre otros.

\section{Ortesis}

Algunos autores afirman que el papel de las ortesis es poco importante ${ }^{6,22}$, especialmente porque no existe ningún estudio que demuestre la capacidad de evitar las contracturas. Por el contrario, hay quienes aseguran que el tratamiento ortopodológico puede devolver la independencia, en cuanto a su deambulación y quehaceres diarios, a una persona sumida en su invalidez física, aumentando su calidad de vida tanto física como psíquicamente ${ }^{9}$. Sin embargo, otros autores que citan las ayudas ortésicas y las férulas en el tratamiento de estos pacientes, no posicionan su opinión acerca de la efectividad de su uso ${ }^{8}$. 
Los objetivos del tratamiento ortopodológico son: eliminar puntos de presión, no corregir la patología sino evitar el aumento de la deformidad, estimular la propiocepción, y permitir la deambulación en la medida de lo posible ${ }^{2}$. Siempre se debe mantener la alineación ósea lo más neutra posible.

Existen una amplia gama de ortesis y se utilizan desde hace muchos años. Diversos autores consideran que las ortesis de cadera y de columna vertebral no son muy efectivas porque son difíciles de tolerar y porque son ineficaces para evitar las deformidades en los niños con parálisis cerebral infanti1 ${ }^{11}$. No obstante, unos ejemplos de ellas pueden ser: los corsés ortopédicos de contención y el bitutor o los bitutores para extremidades inferiores.

Los soportes plantares no sólo mejoran el apoyo de los pies, sino la funcionalidad del paso, las compensaciones posturales, la calidad de la información sensorial y la posible organización del movimiento del niño, previniendo de esta forma la aparición de úlceras por presión, helomas, dolor, roces, hiperqueratosis... ${ }^{4}$, 9 .

Los antiequinos son las ortesis tobillo-pie o AFOs (Fig. 16) más utilizadas en niños pequeños con parálisis cerebral infantil. Dentro de este grupo podemos encontrar diferentes modelos: el bitutor antiequino o bitutor corto (una modificación de éste séria el bitutor tipo Klenzack), la férula tipo "Rancho de Los Amigos", la férula funcional Jousto, el antiequino postural nocturno, el antiequino espiral de plexidur, la ortesis zapato de Giontella o el mue lle de Codivilla. Éstas medidas van a disminuir el gasto energético y van a permitir realizar desplazamientos más largos ${ }^{9,11,23}$. También poseen ciertos inconvenientes como es el posible desarrollo de úlceras por una mala adaptación, atrofia muscular, una disminución en la amplitud de movimiento articular y una reducción de la propiocepción del segmento inferior del niño. Además, la aplicación de AFOs y KAFOs de termoplásticos de polipropilenos supone un coste elevado, un tiempo de trabajo prolongado, y su confección no está muy extendida a nivel podológico ${ }^{2,23}$.

Las ortesis de rodilla-tobillo-pie o KAFOs se suelen utilizar de forma temporal tras la cirugía de la contractura en flexión de rodilla permitiendo al cuádriceps recuperar su fuerza muscular, aunque también se usan en secuelas paralíticas compensando las desviaciones y/o limitaciones producidas. Dentro de este apartado podemos encontrar: ortesis termoconformada para control de la estabilidad mediolateral del tobillo y/o rodilla, ortesis termoconformada para control de la flexión dorsoplantar y estabilidad mediolateral del tobillo, férula termoconformada estabilizadora de la rodilla, bitutor largo por encima de la rodilla, bitutores termoconformados, bitutores mixtos, elementos correctores adicionales... ${ }^{11}$ También existen férulas exclusivas de rodilla o KOs (Fig 17) para control articular. Los materiales empleados para la realización de estas férulas termoconformadas suelen ser polipropilenos, o material termoplástico de baja temperatura (Fig. 18) que permite adaptación directa de la férula sobre el paciente sin un molde previo.

A parte las ortesis termoconformadas podemos encontrar férulas de escayola, cuyo objetivo es mantener el músculo estirado mientras el niño crece. Un ejemplo de ellos son los standing, los standing en aducción y los ministanding, de los que ya hemos hablado an-

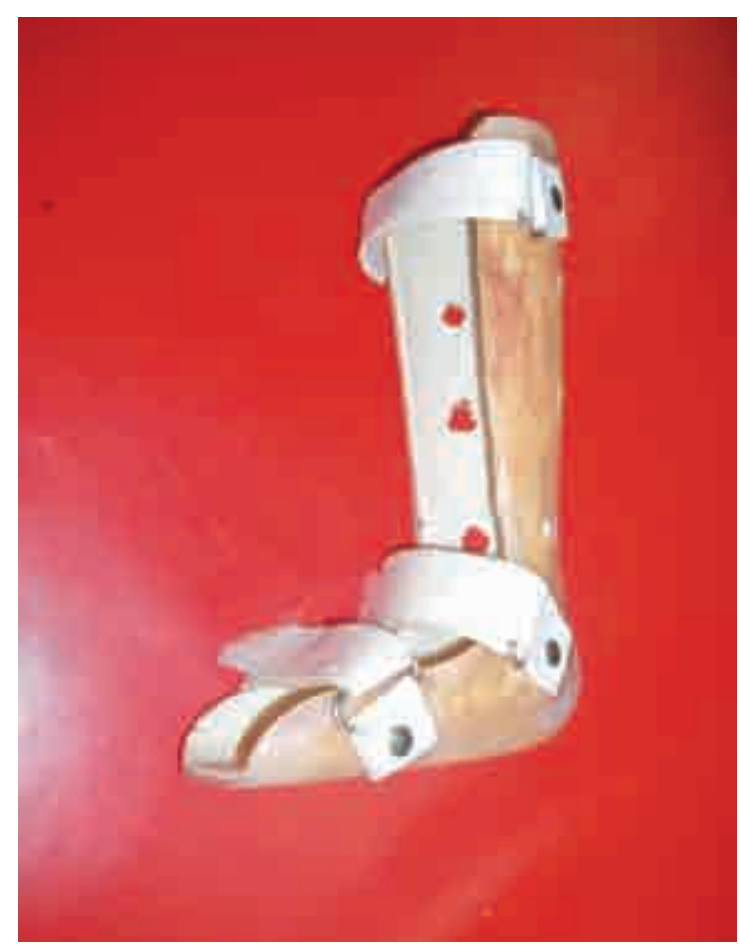

Fig. 16. Ortesis tobillo-pie antiequina. 
teriormente. La utilización de estas medidas en largos periodos puede verse limitado por la necesidad del niño de moverse y de participar en diversas actividades ${ }^{22}$. También podríamos incluir otro tipo de ayudas dentro de este apartado como son las férulas posturales nocturnas, confeccionadas en diversos materiales con el fin de mantener esa corrección mientras el niño duerme ${ }^{10}$.

Todas estas modificaciones tienen repercusión en la marcha del individuo a través de modificaciones funcionales.

\section{- Medicación}

Los estudios clínicos publicados acerca de su uso no determinan de forma clara si son o no eficaces en la parálisis cerebral, ni cuándo es el mejor momento de utilización y cómo controlar su toxicidad ${ }^{24}$. Su uso requiere un programa de fisioterapia intensivo si queremos que los efectos obtenidos se prolonguen en el tiempo.

\section{- Inyecciones intramusculares}

Estas inyecciones pueden contener etanol al $45 \%$, o bien toxina botulínica tipo A. En este caso, nos seguimos encontrando con el problema de que la duración de la reducción de la espasticidad es escasa. Se suele aplicar en gemelos, aductor mayor y bíceps braquial.

\section{CIRUGÍA ORTOPÉDICA}

Existen también soluciones quirúrgicas para los problemas ocasionados por la parálisis cerebral infantil, pero requieren exploraciones clínicas repetitivas, cuidadosas y detalladas ${ }^{22}$, que contenga un análisis minucioso del ciclo de la marcha y de las alteraciones funcionales del paciente. Estas intervenciones quirúrgicas se emplean exclusivamente cuando las medidas ortopédicas han fracasado, cuando el tratamiento conservador origina mas problemas que soluciones, o cuando los problemas ocasionados por la parálisis cerebral son tan severos que impiden la utilización de las mismas.

Se puede intervenir a estos niños en cualquier edad, sin embargo, los mejores resultados funcionales tanto a nivel de las extremidades superiores como inferiores parecen obtenerse entre los 5 y los 7 años de edad (excepto en la prevención de la luxación de cadera que se debe llevar a cabo antes de los 5 años). Las medidas quirúrgicas más utilizadas en el miembro inferior van indicadas a corregir las siguientes patologías:

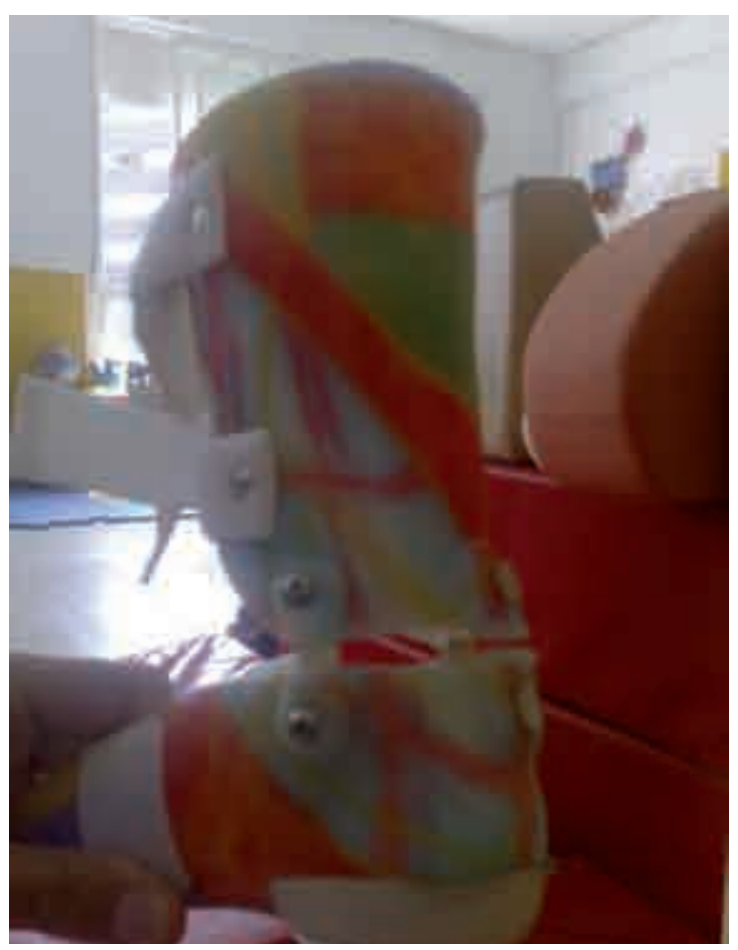

Fig. 17. Ortesis de rodilla.

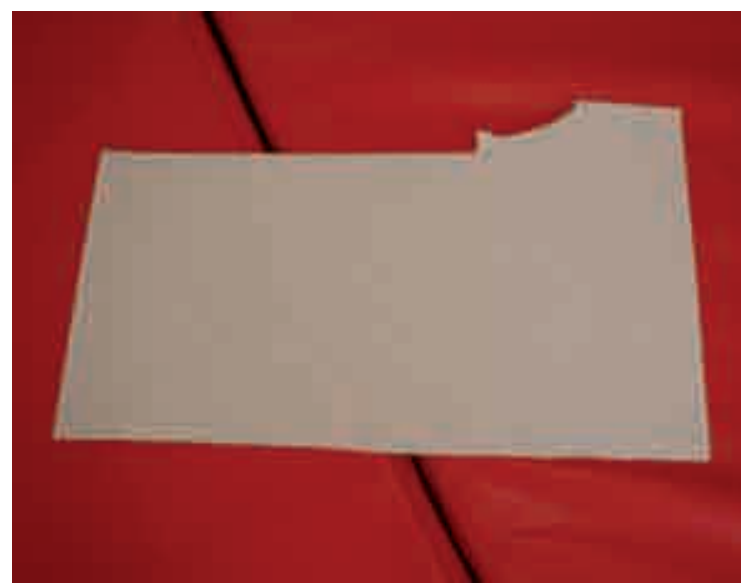

Fig. 18. Lámina de material termoplástico de baja temperatura. 


\section{- Equinismo}

Consiste en el alargamiento del tendón de Aqui les por medio de diferentes métodos como el deslizamiento o la vía percutánea entre otros. La mayor complicación de esta intervención es el sobrealargamiento, ya que produce una deformidad calcánea y un menor control de la fase estática de la marcha.

\section{- Pie varo}

Se produce por un desequilibrio muscular entre el tendón del tibial posterior y los músculos perineos, que suele asociarse a acortamientos del tendón de Aquiles. La cirugía puede centrarse en una triple artrodesis con alargamiento del tendón de Aquiles, o en la transferencia de una bandolera de la mitad del grosor del tendón del tibial posterior al tendón del peroneo lateral corto $^{22}$.

\section{- Pie valgo}

Se suele asociar también con equinismo. Esta deformidad se puede corregir espontáneamente cuando el niño comience a caminar, y no suele ser intervenida hasta después de los 6 años. La intervención más utilizada es la artrodesis subastragalina extraarticular.

\section{- Metatarso adducto}

Esta deformidad puede aparecer en algunos pacientes. La cirugía puede centrarse en una osteotomía metatarsiana si la deformidad es fija, o bien en la escisión de 1-1'5 cm del tendón del abductor del hallux seguido de yeso postoperatorio.

\section{- Flexo de cadera}

Suele aparecer en la diplejia espástica a consecuencia de un acortamiento del músculo psoasiliaco. La intervención está indicada cuando la contractura sea mayor de $15-20^{\circ}$.

El tratamiento consiste en alargar el tendón, o bien en suturarle a la base de la cápsula anterior de la cadera.

\section{- Espasticidad y contractura de la cadera en aducción}

Se interviene para estabilizar la marcha durante la fase de apoyo. Está indicado cuando la abducción está limitada en $20-30^{\circ}$ con las caderas extendidas. Se lleva a cabo mediante una mio- tomía, o mediante la transferencia de las inserciones púbicas de los aductores en el isquion.

\section{- Rotación interna de la cadera}

En este caso, la forma más adecuada de corregir la deformidad se lleva a cabo mediante una osteotomía femoral desrotatoria.

\section{- Luxación y subluxación de cadera}

Producida por el retraso en la deambulación y por la espasticidad de la musculatura aductora y flexora. La solución es una miotomía de dichos tendones, si el niño es menor a 5 años; o bien, una miotomía unida a una osteotomía femoral desrotatoria, si es mayor a 5 años, o incluso puede llegar a hacerse una reconstrucción acetabular.

\section{- Flexión de rodilla}

Por retracción y acortamiento de los músculos isquiotibiales, que afectan a la eficacia de la marcha. La intervención recomendada y preferida consiste en la realización del alargamiento fraccionado de semimembanoso, semitendinoso, y de bíceps femoral, aplicando yesos con la rodilla en extensión durante 3 semanas. También se puede acompañar de una capsulectomía posterior de la articulación de la rodilla.

No obstante, para todas estas patologías existen múltiples alternativas ortopédicas que pueden ayudar a evitar la progresión de las deformidades, a mejorarlas e incluso a corregirlas. A pesar de todo ello, hay autores que consideran que la única solución para el problema de la parálisis cerebral es su prevención ${ }^{22}$.

\section{DISCUSIÓN}

El sistema nervioso es una de las estructuras más complicadas de que consta el ser humano y la más importante para su buen funcionamiento. Un pequeño fallo o lesión en cualquiera de las partes que lo componen puede ser causa de una gran disfunción. Su estudio resulta difícil, dada su gran complejidad en funciones y componentes, muchos de los cuales sin descubrir y comprender, pero resulta imprescindible para llegar a entender los procesos normales y las alteraciones ${ }^{9}$. 
El tratamiento de estos niños con PCI debe ser un tratamiento continuo que no debe centrarse únicamente en la rehabilitación, sino que el propio entorno familiar y social del niño deben colaborar de manera activa en el tratamiento del mismo, previniendo y corrigiendo en todo momento las posibles alteraciones que puedan aparecer ${ }^{25}$.

De todo lo expuesto, se deduce, que en el tratamiento de las afecciones debe prevalecer un criterio sencillo, concreto y funcional, encaminado al posterior desarrollo motor del niño y a su integración en una vida infantil que se acerque lo más posible a la normalidad ${ }^{21}$.

Hay diversos autores que no tienen en cuenta las medidas ortopodológicas como medidas terapéuticas en el tratamiento de las deformidades musculoesqueléticas de los niños con parálisis cerebral infantil, sino que centran la rehabilitación de los mismos en un tratamiento fisioterapéutico individualizado y lo más precoz posible, pudiéndolo combinar con la cirugía $^{6,22}$. Otros en cambio ${ }^{9,26}$ afirman que mediante un tratamiento ortopodológico adecuado se retrasa la progresión de las deformidades y retracciones propias de una parálisis o hemiplejía mejorando la funcionalidad, disminuyendo la sintomatología, y evitando así, la aparición de otros problemas asociados que contribuyen a aumentar toda la problemática existente. El tratamiento ortopodológico puede resultar insuficiente si no va acompañado de un calzado adecuado que, sin ferulizar los movimientos del pie, dote de una contención del mismo, o de otras medidas terapéuticas como vendajes funcionales, estiramientos, tonificación o estimulación.

\section{CONCLUSIONES}

Las ayudas para la marcha son herramientas que favorecen la deambulación normal del niño. Actualmente existen en el mercado una amplia gama de modelos y de adaptaciones de estas ayudas que permiten llevar a cabo un tratamiento íntegro de los déficits de movilidad; no obstante, debemos realizar anteriormente un buen análisis tanto de las carencias como de los objetivos a tener en cuenta de cara a la rehabilitación para poder llevarlo a cabo de la mejor manera posible.

Las medidas conservadoras han de utilizarse siempre en primer lugar antes de optar por una intervención quirúrgica, puesto que podemos obtener en muchos casos los mismos resultados sin tener la necesidad de correr los riesgos que una operación puede ocasionar.

A la hora de afrontar estos desórdenes es imprescindible contar con un equipo multidisciplinar que trabaje de forma coordinada para proporcionarle al paciente la independencia necesaria para llevar a cabo una vida que se acerque lo máximo posible a la normalidad.

Del mismo modo se requiere la implicación familiar y social en el tratamiento, favoreciendo en todo momento que el entorno en el que se encuentra el paciente no sea una cosa lejana a la realidad sino que cuente con las adaptaciones y facilidades necesarias para llevar a cabo la eliminación de muchas de las barreras tanto arquitectónicas como físicas que aparecen en la vida diaria de estos pacientes.

\section{AGRADECIMIENTOS}

Agradezco la colaboración de Elisa y Melisa, fisioterapeutas del Colegio Público de Infantil y Primaria Méjico, de Madrid, por haber permitido obtener las fotografías que se observan en este artículo.

\section{BIBLIOGRAFÍA}

1. López Ros P, Pascual Gutiérrez R, Monzó Pérez F, Moltó Valor A, Remón Lara J. Parálisis cerebral infantil. Podol clin. 2003;4(2):56-64.

2. Ros P, Pascual Gutiérrez R, Monzó Pérez F, García Blázquez-Pérez F. Parálisis cerebral infantil: aplicación de férulas de materiales plásticos. Salud del pie: Rev Esp Podol. 2003;30:20-29. 
3. Camilieri Rumbau MM. Toxina botulínica y fisioterapia en la parálisis cerebral infantil. Rev fisioter (Guadalupe). 2006;5(1):19-26.

4. Gijón Nogueron G. Tratamientos ortopodológicos en casos de síndromes neurológicos. Rev Esp Podol. 2000;XI(5):333-339.

5. Schutt A. Cerebral palsy. En: Sinaki M, ed. Basic clinical rehabilitation medicine. $2^{\mathrm{a}}$ ed. San Luis: Mosby; 1993 :377-378.

6. García Díez E, Capablo Mañas B. Valoración y estudio de las deformidades ortopédicas en personas con parálisis cerebral. Fisioterapia. 1999;21(1):10-19.

7. Root L. Varus and valgus foot in CP and its management. Foot and ankle, 1984;4(4):174-179.

8. Levitt S. Tratamiento de la parálisis cerebral y del retraso motor. $3^{\mathrm{a}}$ ed., $1^{\mathrm{a}}$ reimp. Madrid: Médica Panamericana, D.L.; 2002.

9. Martínez Espinosa O, Morey Torrandell C. Alternativas ortopodológicas en marchas neurológicas. Rev Esp Podol. 1998;IX(7):332-380.

10. García Pérez F. Utilización de ayudas técnicas en 24 adultos jóvenes con secuelas motoras de parálisis cerebral infantil. Rehabilitación. 1999;33(4):255-265.

11. Viladot R, Cohi O, Clavell S. Ortesis y prótesis del aparato locomotor.2.2 Extremidad inferior. Barcelona: Masson; 2005.

12. Kasser J, Macewn G. Examination of cerebral palsy pattern with foot and ankle problems. Foot and ankle. 1983;4(3):135-144.

13. Amiel-Tison C, Grenier A. Vigilancia neurológia durante el primer año de vida. Barcelona: Masson; 1988.

14. Pountney T, Green E. Parálisis cerebral y tastornos del aprendizaje común. En: Stokes M. Fisioterapia en la Rehabilitación Neurológica. 2a Edición. Barcelona: Elsevier; 2006. p. 339-359.

15. Macias Merlo ML, Fagoaga Mata J. Fisioterapia en pediatría. Madrid: McGraw-Hill Interamericana; 2006.

16. Macias Merlo ML. Andador con soporte ventral. Fisioterapia. 1986;31:9-11.

17. Cruz Hernández R. Valoración de la discapacidad en parálisis cerebral. Rehabilitación. 1997;31(6):457463.

18. Macias Merlo ML. Niños con parálisis cerebral severa: planificar su rehabilitación. Rev Rol Enferm. 1983;63-64:39-41.

19. Alonso Ibáñez ML, Clemente García MR. Parálisis cerebral infantil: tratamiento multidisciplinar. A propósito de un caso. Salus pie. 2006;40:22-28.

20. Pascual Gutiérrez R, López Ros P, Alonso Montero C. Marcha infantil. Rev Esp Podol. 2001;XII(2): 89-96.

21. Serra Gabriel MR. La técnica ortopédica en el recién nacido y lactante. Fisioterapia. 1983;18:23-26.

22. Bleck EE. Tratamiento de la parálisis cerebral. Rev Ortop Traumatol. 1997;41(4):437-448.

23. Céspedes Céspedes T, Dorca Coll A, Concustell Gonfaus J, Sacristán Valero S. Aplicación de las férulas funcionales en las marchas neurológicas. Rev Esp Podol. 1997;VIII(8):426-431.

24. Blackman JA, Reed MD, Roberts CD. Muscle relaxant drugs for children with cerebral palsy. En: Sussman MD, ed. The diplegic child evaluation and management. Rosemont. AAOS, 1999, 229-239.

25. Cruz Hernández R, Gimeno Esteve F, Cabezuelo Briones A, Olona M. Adaptación de la clasificación internacional de deficiencias, discapacidades y minusvalías a la parálisis cerebral: fiabilidad de la escala de severidad en la valoración de las discapacidades. Rehabilitación. 1997;31(5):343-349.

26. Lafuente Sotillos G, Prats Climent B. Ortopodología infantil. Rev Esp Podol. 2006;XVII(6):256-261. 